\title{
The potential for PET-guided revascularization of coronary artery disease
}

\author{
Matthieu Pelletier-Galarneau ${ }^{1,2} \cdot$ Terrence D. Ruddy $^{3}$
}

Received: 14 March 2019 / Accepted: 21 March 2019 / Published online: 2 April 2019

(C) Springer-Verlag GmbH Germany, part of Springer Nature 2019

Over the past two decades, positron emission tomography (PET) has been very useful for the diagnosis and staging of various cancers and successful for guiding therapy [1]. A striking illustration is the use of ${ }^{18} \mathrm{~F}$-fluorodeoxyglucose (FDG) PET to guide chemotherapy in patients with lymphoma. For example, in patients with limited-stage Hodgkin's lymphoma, FDG PET can be performed after two cycles of chemotherapy to establish disease activity. Persistent disease on PET will trigger a change in chemotherapeutic agents and higher radiation therapy doses, while a negative PET study will result in shorter therapy and lower radiation therapy doses with better patient outcomes $[2,3]$. This is one of many effective PET-guided interventions in oncology. In contrast, demonstration of the effectiveness of PET-guided therapy for cardiovascular applications has been more challenging. For example, the PARR-2 trial [4] was a randomized controlled trial designed to evaluate the role of myocardial viability assessment with FDG PET to guide revascularization in patients with severe left ventricular dysfunction. Although the study concept was supported by much clinical evidence and rooted in strong physiology, it failed to demonstrate a significant benefit for the PET-guided management versus standard care. Interestingly, a single-site post hoc analysis showed that the adverse outcome rate was significantly lower when revascularization was concordant with the PET recommendation, compared to revascularization discordant with the PET recommendation [5]. These better outcomes with concordant PET

Terrence D. Ruddy

TRuddy@ottawaheart.ca

1 Department of Medical Imaging, Montreal Heart Institute, Montreal, Quebec, Canada

2 Gordon Center for Medical Imaging, Massachusetts General Hospital, Harvard Medical School, Boston, MA, USA

3 Division of Cardiology, Department of Medicine, University of Ottawa Heart Institute, 40 Ruskin Street, Ottawa, ON K1Y 4W7, Canada and revascularization may reflect optimal patient management in centers with integrated imaging, heart failure and surgical teams and clinical management teams, a factor which was not accounted for in the original trial. Similarly, other clinical factors may influence the decision for a specific therapy more than the PET result and lead to discordant PET revascularization decisions. Thus, implementation of a robust prospective clinical trial to determine the efficacy of cardiac PET-guided therapy may be particularly difficult.

PET myocardial perfusion imaging (MPI) has been repeatedly shown to be accurate for the detection and risk stratification of obstructive coronary artery disease (CAD) [6]. In addition, PET MPI allows accurate quantification of global and regional myocardial blood flow (MBF) [7] and has improved risk stratification in ischemic and non-ischemic cardiomyopathy [8-14], facilitated assessment of the coronary response to various interventions $[15,16]$, and improved detection of balanced ischemia [17]. Decision making for revascularization in stable CAD has been guided for many years by the presence of ischemia shown by reversible perfusion defects on MPI. The concept that patients with large areas of ischemia ( $>10 \%$ to $15 \%$ of the left ventricle) have better outcomes with revascularization than with medical therapy is well accepted and is based on large observational SPECT studies [18, 19]. However, more recent large randomized controlled trials, such as COURAGE and STICH, failed to show a benefit of revascularization over medical therapy [20,21]. On the other hand, the FAME and FAME-II trials demonstrated that revascularization guided by fractional flow reserve (FFR) significantly improves patient outcomes [22, 23]. Thus, revascularization based solely on anatomic angiographic stenosis and not physiologic flow impairment may have suboptimal outcomes and explain in part the disappointing results of the COURAGE and STICH trials. Since PET can quantify regional MBF, PET may be useful for guiding the selection of patients for revascularization and specific vessels for grafting.

In this issue of the European Journal of Nuclear Medicine and Molecular Imaging, Bober et al. [24] report a study of the 
impact of revascularization on stress MBF, expanding on their previous retrospective study [25]. The study included 50 patients who underwent ${ }^{82} \mathrm{Rb}$ PET MPI as a clinical study before revascularization and then underwent a second ${ }^{82}$ Rb PET MPI study prospectively as a research study within 90 days. Participants were enrolled in the study after successful revascularization, allowing a stenosis-based "standard practice" revascularization decision. The myocardium was divided into four quadrants based on the epicardial coronary anatomy and PET perfusion pattern. The quadrants were classified into four categories using the pre-revascularization PET study were based on the relative perfusion images (presence or absence of ischemia $>10 \%$ ) and the coronary flow capacity (CFC, severely reduced or not). $\mathrm{CFC}$ is a metric combining stress $\mathrm{MBF}$ and coronary flow reserve (CFR, stress to rest MBF ratio). Regions with both abnormal relative MPI and severely reduced CFC showed a significant increase of $59 \%$ in stress MBF following revascularization. Regions with normal MPI but severely reduced CFC also showed a significant improvement in stress $\mathrm{MBF}$ of $40 \%$ following revascularization. Conversely, revascularization did not increase stress MBF in normal myocardial regions, defined as absence of ischemia on relative MPI and normal CFC. Importantly, no significant changes in stress MBF were found in regions without revascularization.

In their study, Bober et al. relied heavily on the concept of CFC, introduced by Johnson and Gould [26] and based on the integration of both stress $\mathrm{MBF}$ and CFR. CFC is used to classify the myocardium into categories of physiologic impairment, with a severe reduction in CFC defined as stress $\mathrm{MBF} \leq 0.91 \mathrm{~cm}^{3} / \mathrm{min} / \mathrm{g}$ and $\mathrm{CFR} \leq 1.74$. The authors suggest that $\mathrm{CFC}$ has advantages over CFR or stress MBF alone, including superior capacity to predict major adverse cardiac events (MACE), although this is controversial [27, 28]. At present, most centers and studies report stress $\mathrm{MBF}$ and CFR [9] and few sites routinely use CFC. To further complicate things, different studies using the same CFC methodology have used different cut-off values to define a severe reduction in CFC (e.g. stress MBF $\leq 0.83 \mathrm{~cm}^{3} / \mathrm{min} / \mathrm{g}$ and $\mathrm{CFR} \leq 1.27$ [27]). In either case, these values for a low CFC are much reduced and identify patients with very severe flow impairment. A better approach to defining CFC abnormality may be receiver operating curve (ROC) analyses applied to large datasets and cut-off criteria optimized for detection of significant coronary flow abnormality identified using another modality such as FFR or by determining prognosis. It remains unknown whether CFC provides incremental information compared to stress $\mathrm{MBF}$ and $\mathrm{CFR}$ in predicting improvement in stress MBF.

A limitation of the study was its susceptibility for regression toward the mean bias. Indeed, the main findings of this study consist of improvement in stress MBF and CFR in regions with lower MBF and CFR values on the initial PET study. Another limitation was the heterogeneity of the study population that included 41 patients undergoing percutaneous coronary interventions (PCI), 7 patients with cardiac bypass surgery, and 2 patients with hybrid revascularization.

PET-guided revascularization requires that MBF measurements are sufficiently accurate. Quantification of global and regional (quadrants) $\mathrm{MBF}$ with ${ }^{82} \mathrm{Rb}$ has been shown to be reasonably accurate, although it can depend on the software and method [29], with a test-retest precision of \pm 10 $20 \%[30,31]$. Still, regional flow accuracy is dependent on count density, and areas with low counts are associated with reconstruction bias [32] and increased noise, both of which can affect quantification significantly. Low-flow regions with reduced count density have greater variability. PET scanners with high count rates, such as the one used by Bober et al., are necessary for adequate MBF quantification [33]; older generation systems, especially those equipped with bismuth germanate (BGO) crystals, are designed for static imaging and may be suboptimal for high count rate dynamic imaging. When using short-lived radiotracers such as ${ }^{82} \mathrm{Rb}$ and ${ }^{15} \mathrm{O}$-water, cameras with high count rate capabilities are necessary to minimize detector saturation and dead-time losses to permit accurate quantification of left ventricular or atrial blood pool first-pass tracer activity. Perhaps only in centers equipped with PET scanners with properties allowing high count rate dynamic images, especially when using ${ }^{82} \mathrm{Rb}$ and ${ }^{15} \mathrm{O}$-water, can $\mathrm{PET}$-guided revascularization be reliably performed.

While a previous study has shown that physiology-guided PCI can predict improvement in hyperemic coronary flow [34], this is the first prospective study demonstrating the ability of PET flow quantification to predict improvement in regional stress MBF on revascularization. We commend the authors for this important work. These results further support the importance of physiologic assessment of coronary stenosis prior to revascularization and the incremental value of quantitative measurement of MBF with relative perfusion imaging. Whether PET-guided revascularization improves symptoms or reduces events still has to be demonstrated and would require a randomized controlled trial of PET-guided revascularization compared to standard care. The results of this study are very encouraging. We need to rise to the challenge to confirm the benefits of PET-guided revascularization with further randomized controlled trials focusing on hard outcomes and using a single revascularization strategy.

Funding Dr. T. Ruddy has received research grant support from GE Healthcare and Advanced Accelerator Applications Inc.

\section{Compliance with ethical standards}

Conflicts of interest Dr. M. Pelletier-Galarneau declares that he has no conflicts of interest. 


\section{References}

1. Yap JT, Carney JPJ, Hall NC, Townsend DW. Image-guided cancer therapy using PET/CT. Cancer J. 2004;10:221-33.

2. Eichenauer DA, Aleman BMP, André M, Federico M, Hutchings M, Illidge T, et al. Hodgkin lymphoma: ESMO clinical practice guidelines for diagnosis, treatment and follow-up. Ann Oncol. 2018;29:iv19-29.

3. Radford J, Illidge T, Counsell N, Hancock B, Pettengell R, Johnson $\mathrm{P}$, et al. Results of a trial of PET-directed therapy for early-stage Hodgkin's lymphoma. N Engl J Med. 2015;372:1598-607.

4. Beanlands RSB, Nichol G, Huszti E, Humen D, Racine N, Freeman $\mathrm{M}$, et al. F-18-fluorodeoxyglucose positron emission tomography imaging-assisted management of patients with severe left ventricular dysfunction and suspected coronary disease: a randomized, controlled trial (PARR-2). J Am Coll Cardiol. 2007;50:2002-12.

5. Abraham A, Nichol G, Williams KA, Guo A, deKemp RA, Garrard $\mathrm{L}$, et al. 18F-FDG PET imaging of myocardial viability in an experienced center with access to $18 \mathrm{~F}-\mathrm{FDG}$ and integration with clinical management teams: the Ottawa-FIVE substudy of the PARR 2 trial. J Nucl Med. 2010;51:567-74.

6. Chareonthaitawee P, Beanlands RS, Chen W, Dorbala S, Miller EJ, Murthy VL, et al. Joint SNMMI-ASNC expert consensus document on the role of $18 \mathrm{~F}-\mathrm{FDG}$ PET/CT in cardiac sarcoid detection and therapy monitoring. J Nucl Med. 2017;58:1341-53.

7. Pelletier-Galarneau M, Martineau P, El Fakhri G. Quantification of PET myocardial blood flow. Curr Cardiol Rep. 2019;21:11.

8. Murthy VL, Naya M, Foster CR, Hainer J, Gaber M, Di Carli G, et al. Improved cardiac risk assessment with noninvasive measures of coronary flow reserve. Circulation. 2011;124:2215-24.

9. Murthy VL, Bateman TM, Beanlands RS, Berman DS, BorgesNeto S, Chareonthaitawee P, et al. Clinical quantification of myocardial blood flow using PET: joint position paper of the SNMMI Cardiovascular Council and the ASNC. J Nucl Med. 2018;59: 273-93.

10. Murthy VL, Naya M, Foster CR, Hainer J, Gaber M, Dorbala S, et al. Coronary vascular dysfunction and prognosis in patients with chronic kidney disease. JACC Cardiovasc Imaging. 2012;5:1025-34.

11. Dorbala S, Vangala D, Bruyere J, Quarta C, Kruger J, Padera R, et al. Coronary microvascular dysfunction is related to abnormalities in myocardial structure and function in cardiac amyloidosis. JACC Heart Fail. 2014;2:358-67.

12. Kalliokoski RJ, Kalliokoski KK, Sundell J, Engblom E, Penttinen $\mathrm{M}$, Kantola I, et al. Impaired myocardial perfusion reserve but preserved peripheral endothelial function in patients with Fabry disease. J Inherit Metab Dis. 2005;28:563-73.

13. Majmudar MD, Murthy VL, Shah RV, Kolli S, Mousavi N, Foster $\mathrm{CR}$, et al. Quantification of coronary flow reserve in patients with ischaemic and non-ischaemic cardiomyopathy and its association with clinical outcomes. Eur Heart J Cardiovasc Imaging. 2015;16: 900-9.

14. McArdle BA, Davies RA, Chen L, Small GR, Ruddy TDR, Dwivedi $\mathrm{G}$, et al. The prognostic value of $\mathrm{Rb}-82$ positron emission tomography in patients following heart transplant. Circ Cardiovasc Imaging. 2014;7:930-7.

15. Pelletier-Galarneau M, deKemp RA, Hunter CRRN, Klein R, Klein $\mathrm{M}$, Ironstone $\mathrm{J}$, et al. Effects of hypercapnia on myocardial blood flow in healthy human subjects. J Nucl Med. 2018;59:100-6.

16. Pelletier-Galarneau M, Hunter CRRN, Ascah KJ, Beanlands RSB, Dwivedi G, deKemp RA, et al. Randomized trial comparing the effects of ticagrelor versus clopidogrel on myocardial perfusion in patients with coronary artery disease. J Am Heart Assoc. 2017;6: e005894.
17. Parkash R, deKemp RA, Ruddy TD, Kitsikis A, Hart R, Beauchesne L, et al. Potential utility of rubidium 82 PET quantification in patients with 3 -vessel coronary artery disease. J Nucl Cardiol. 2004;11:440-9.

18. Hachamovitch R, Hayes SW, Friedman JD, Cohen I, Berman DS. Comparison of the short-term survival benefit associated with revascularization compared with medical therapy in patients with no prior coronary artery disease undergoing stress myocardial perfusion single photon emission computed tomography. Circulation. 2003;107:2900-7.

19. Hachamovitch R, Rozanski A, Shaw LJ, Stone GW, Thomson LEJ, Friedman JD, et al. Impact of ischaemia and scar on the therapeutic benefit derived from myocardial revascularization vs. medical therapy among patients undergoing stress-rest myocardial perfusion scintigraphy. Eur Heart J. 2011;32:1012-24.

20. Boden WE, O'Rourke RA, Teo KK, Hartigan PM, Maron DJ, Kostuk WJ, et al. Optimal medical therapy with or without PCI for stable coronary disease. N Engl J Med. 2007;356:1503-16.

21. Velazquez EJ, Lee KL, Deja MA, Jain A, Sopko G, Marchenko A, et al. Coronary-artery bypass surgery in patients with left ventricular dysfunction. N Engl J Med. 2011;364:1607-16.

22. Tonino PAL, De Bruyne B, Pijls NHJ, Siebert U, Ikeno F, van't Veer M, et al. Fractional flow reserve versus angiography for guiding percutaneous coronary intervention. N Engl J Med. 2009;360: 213-24.

23. Xaplanteris P, Fournier S, Pijls NHJ, Fearon WF, Barbato E, Tonino PAL, et al. Five-year outcomes with PCI guided by fractional flow reserve. N Engl J Med. 2018;379:250-9.

24. Bober RM, Milani RV, Oktay AA, Javed F, Polin NM, Morin DP. The impact of revascularization on myocardial blood flow as assessed by positron emission tomography. Eur J Nucl Med Mol Imaging. 2019. https://doi.org/10.1007/s00259-019-04278-8.

25. Bober RM, Thompson CD, Morin DP. The effect of coronary revascularization on regional myocardial blood flow as assessed by stress positron emission tomography. J Nucl Cardiol. 2017;24: 961-74.

26. Johnson NP, Gould KL. Integrating noninvasive absolute flow, coronary flow reserve, and ischemic thresholds into a comprehensive map of physiological severity. JACC Cardiovasc Imaging. 2012;5: 430-40.

27. Gould KL, Johnson NP, Roby AE, Nguyen T, Kirkeeide R, Haynie $\mathrm{M}$, et al. Regional, artery-specific thresholds of quantitative myocardial perfusion by PET associated with reduced myocardial infarction and death after revascularization in stable coronary artery disease. J Nucl Med. 2019;60:410-7.

28. Di Carli MF, Hachamovitch R. Quantitative coronary flow capacity for risk stratification and clinical decision making: is it ready for prime time? J Nucl Med. 2019;60:407-9.

29. Tahari AK, Lee A, Rajaram M, Fukushima K, Lodge MA, Lee BC, et al. Absolute myocardial flow quantification with $82 \mathrm{Rb}$ PET/CT: comparison of different software packages and methods. Eur J Nucl Med Mol Imaging. 2014;41:126-35.

30. Kitkungvan D, Johnson NP, Roby AE, Patel MB, Kirkeeide R, Gould KL. Routine clinical quantitative rest stress myocardial perfusion for managing coronary artery disease. JACC Cardiovasc Imaging. 2017;10:565-77.

31. Efseaff M, Klein R, Ziadi MC, Beanlands RS, deKemp RA. Shortterm repeatability of resting myocardial blood flow measurements using rubidium-82 PET imaging. J Nucl Cardiol. 2012;19:9971006.

32. Walker MD, Asselin M-C, Julyan PJ, Feldmann M, Talbot PS, Jones $\mathrm{T}$, et al. Bias in iterative reconstruction of low-statistics PET data: benefits of a resolution model. Phys Med Biol. 2011;56:931-49.

33. Moody JB, Lee BC, Corbett JR, Ficaro EP, Murthy VL. Precision and accuracy of clinical quantification of myocardial blood flow by 
dynamic PET: a technical perspective. J Nucl Cardiol. 2015;22: 935-51.

34. Nijjer SS, Petraco R, van de Hoef TP, Sen S, van Lavieren MA, Foale RA, et al. Change in coronary blood flow after percutaneous coronary intervention in relation to baseline lesion physiology: results of the JUSTIFY-PCI study. Circ Cardiovasc Interv. 2015;8: e001715.
Publisher's note Springer Nature remains neutral with regard to jurisdictional claims in published maps and institutional affiliations. 